\title{
A homofobia como uma das faces do bullying: análise em periódicos científicos da Educação Física
}

\author{
Galdino Rodrigues de Sousa' \\ Fabiono Pries Devide ${ }^{2}$ \\ Talita de Resende Andrade ${ }^{3}$ \\ Elaine Valério Rizzuti ${ }^{4}$
}

\section{RESUMO}

Considerando a incidência das questões de gênero nas Escolas, as mais variadas formas de bullying e a alta expressividade desse fenômeno nas aulas de Educação Física escolar, tivemos como objetivo mapear artigos a respeito dessa temática em quatro periódicos da área, bem como sua possível relação com a homofobia ou bullying homofóbico. Estabelecemos algumas questões norteadoras, a saber: Com que intensidade os principais periódicos da Educação Física trazem artigos voltados para a discussão do bullying? Quais as principais características e os principais objetivos dessas investigações? Existem artigos que estabelecem relação entre o fenômeno bullying e a homofobia? O resultado encontrado assinala escassos os estudos sobre o bullying e a homofobia, sendo poucas também as estratégias possíveis de intervenção e alternativas para minimizar seus eventuais conflitos. Acerca da discussão sobre bullying homofóbico, não foram encontrados resultados em nossa pesquisa.

Palavras-chave: Periódicos científicos. Educação física. Bullying homofóbico

1 Mestre em Educação. Doutorando em Educação Física (UFES) e Professor substituto dos cursos de licenciatura e bacharelado em Educação Física da Universidade Federal do Espírito Santo (UFES). Vitória/ Espírito Santo, Brasil. E-mail: galdinorodrigues@yahoo.com.br

2 Doutor em Educação Física. Professor adjunto do curso de licenciatura em Educação Física da Universidade Federal Fluminense (UFF). Niterói/ Rio de Janeiro, Brasil. E-mail: fabianodevide@uol.com.br

3 Licenciada em Educação Física pela Universidade Federal de São João del-Rei (UFSJ). São João del-Rei/ Minas Gerais, Brasil. E-mail: talita.randrade@hotmail.com

4 Doutora em Educação Física. Professora adjunta do curso de licenciatura em Educação Física da Universidade Federal de São João del-Rei (UFSJ). São João del-Rei/ Minas Gerais, Brasil. E-mail: elainerizzuti@terra.com.br

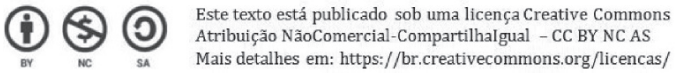




\title{
Homofophobia as one of the faces of the bullying: in analysis in scientific newspapers of Physical Education
}

\begin{abstract}
Considering the incidence of gender issues at schools, the most different kinds of bullying and the high expressive incidence of this phenomenon happens in Physical Education classes. We established like thas ane objective to map articles about this thematic in four journals from Physical Education area. Said that, we tried to see a possible relation between the homophoby and the homophobic bullying throughout these journals. We established some guiding issues, for instance: How often do the main Physical Education journals bring overturned articles for discussion of bullying? What are the main characteristics and main objectives of these investigations? Are there articles that link bullying and homophobia? The result has pointed out that there are rare studies on bullying and homophobia, being few also are possible intervention strategies and alternatives to minimize possible conflicts. The discussion of homophobic bullying did not appear in any of our investigation.
\end{abstract}

Keywords: Cientific journals. Physical education. Homophobic bullying

La homofobia como una de las caras del bullying: análisis em revistas de Educación Física

\section{RESUMEN}

Considerando la incidencia de las cuestiones de genero en las escuelas, las mas variadas formas de bullying y la alta expresividad de este fenómeno en las clases de Educación Física escolar, establecemos como objetivo mapear artículos al respecto de esta temática en cuatro periódicos del área de Educación Física bien como su posible relación con la homofobia o bullying homofóbico. Establecemos algunas cuestiones norteadoras: ¿Con que intesidad los principales periódicos de la Educación Física traen artículos volteados para la discusión del bullying? ¿Cuáles son las principales características y los objetivos principales de estas investigaciones? ¿Existen artículos que establecen relación entre el fenómeno bullying y la homofobia? El resultado encontrado señala escasos estudios sobre el bullying y homofobia, es muiy pocos las posibles estrategias de intervención y alternativas para minimizar los eventuales conflictos. La discusión de bullying homofóbico no presento resultados en nuestra investigación.

Palabras clave: Periódicos científicos. Educación física. Bullying homofóbico 


\section{INTRODUÇÃO}

Toda ação ou gesto traduz elementos culturais aprendidos pelos indivíduos de acordo com o lugar social ao qual pertencem (LARAIA, 2002). Essa construção cultural, que se dá na relação com o outro e com diversas instâncias sociais (família, escola, trabalho, igreja, mídia), contribui para que sejam formadas identidades - de gênero, sexual, racial, étnica, dentre outras. Tais formações identitárias nem sempre são entendidas e aceitas, sendo necessárias problematizações.

Nesse contexto, a intolerância ou não aceitação se efetiva, principalmente, em espaços que concebem pessoas de variadas culturas como a escola. Esse processo violento, vivido por milhares de pessoas, tem como nomenclatura a palavra bullying ${ }^{5}$ e como principal característica a recorrência de atitudes que envolvem violência ${ }^{6}$ psicológica, física, negligencial, pratimonial, etc. contra aqueles/as entendidos/as como "diferentes", seja por questões de raça, etnia, classe, religião ou gênero.

Caracterizado por xingamentos, deboches e piadas, o bullying, quando desencadeado em espaços escolares, traz consequências indesejáveis no processo de ensino aprendizagem e na própria vida dos indivíduos que dele sofrem, podendo acarretar até mesmo o suicídio. Essas agressões, à primeira vista, não apresentam relevância e são tidas como inofensivas. Todavia, apenas quem é alvo consegue ter a devida noção do sofrimento psíquico e da sensação de humilhação que elas desencadeiam (CANDAU, 2003).

O corpo, conforme Le Breton (2006) é um fio condutor fértil de representações e imaginários daquilo que constitui os seres. Assim, muitos estigmas fundantes da prática de bullying, característicos das vítimas que sofrem essa violência, são externalizados pelas práticas corporais nos mais variados espaços de convivência.

A Educação Física é uma das disciplinas escolares que aborda questões relacionadas ao corpo, pois é a partir dele que fundamenta suas atividades pedagógicas. Soares et. al (1992), caracteriza essa disciplina como a que pedagogiza elementos de uma área denominada cultura corporal de movimento, buscando desenvolver diferentes dimensões da expressão corporal. É na perspectiva do trabalho com o corpo, para o corpo e partir do corpo, que a Educação Física, por meio de diálogos com as ciências humanas e sociais, surge como potencial problematizadora para os diferentes tipos de bullyng.

Em síntese, nas aulas de Educação Física, as formas de bullying tendem a exprimir-se com mais veemência devido à socialização marcada pelas práticas corporais grupais que deixam os significados culturais - e suas diferenças - mais expostos (LOUZADA, DEVIDE, 2006). A escolha de determinadas atividades ainda taxadas pela sociedade como "de meninos" e "de meninas", como exemplo a dança, também aparece como potencializadora

5 Para Lisboa; Braga; Ebert (2009) não existe tradução literal consensual da palavra Bullying para o Português, podendo ser entendido semanticamente por "intimidação".

6 Para Minayo (1998; in Lech; 2007), a "violência consiste em ações humanas de indivíduos ou grupos, classes, nações que afetam a integridade física, moral, mental ou espiritual, podendo ocasionar a morte" (p. 44). 
dessa discussão, contribuindo para que emerja o bullying direcionado à identidade sexual dos estudantes ou o bullying homofóbico ${ }^{7}$.

Considerando que existem as mais variadas formas de bullying e a alta expressividade desse fenômeno nas aulas de Educação Física, nos sentimos instigados a investigar às seguintes questões:

i. Com que intensidade os principais periódicos da Educação Física publicam artigos voltados para a discussão do bullying?

ii. Quais as principiais características e os principais objetivos dessas investigações?

iii. Existem artigos que estabelecem relação entre o fenômeno bullying e a homofobia?

Desenvolvemos a pesquisa com o objetivo de analisar artigos da área de Educação Física direcionados para a discussão do bullying, enfatizando também sua possível relação com a homofobia ou bullying homofóbico. O intuito deste trabalho não foi o de esgotar tais questionamentos ou as potenciais reflexões que deles possam emergir, mas, ao contrário, buscamos constatações preliminares que nos permitissem avançar nesse território ainda pouco explorado nas produções da Educação Física.

O bullying homofóbico ${ }^{8}$ pode se caracterizar pela incitação ao ódio, à perseguição, à difamação e/ou à violência contra pessoas que possuem identidade sexual diferentes da heterossexual. Porém, o indivíduo não precisa ser gay, lésbica, bissexual ou transexual para sofrer dessa violência, basta que possua trejeitos ou escolhas que aparentem características de homossexuais, lésbicas, bissexuais ou transexuais, vistas como socialmente "inadequadas" à identidade de gênero heterossexual. É preciso combater esse tipo de violência cada vez mais crescente, sendo esse um dever no Estado, de suas esferas e de seus representantes.

A relevância científica desta pesquisa se dá na investigação de relações sociais e culturais de formas de violência que, por vezes, adentram o ambiente escolar e são tratadas como irrelevantes, em ocasião, principalmente do despreparo dos agentes que nela estão inseridos. A sistematização e análise dos artigos que tratam da temática pesquisada podem contribuir para que tenhamos um panorama a respeito do estado atual das pesquisas que analisam o fenômeno bullying na área de Educação Física, em especial do bullying homofóbico. Tais informações podem fundamentar professores/pesquisadores da área em suas práticas pedagógicas e futuras investigações.

\section{REFERENCIAL TEÓRICO METODOLÓGICO}

Este estudo é de natureza qualitativa, descritiva e exploratória, tendo como elementos estruturantes a revisão bibliográfica e a análise dos artigos encontrados. Segundo

7 A Organização das Nações Unidas para a Educação, Ciência e Cultura (UNESCO), define o bulliyng homofóbico como aquele que é exercido com base na identidade sexual percebida ou na identidade de gênero, sendo um tipo específico de intimidação que se define pelo assédio homofóbico.

8 Apesar de, para fins desse estudo, fazermos uso do termo "bullying homofóbico", reconhecemos que esse incorpora a lesbofobia, a transfobia e a bifobia. 
Alves-Mazzotti e Gewandsznajder (2002), esse método permite a descrição do fenômeno investigado, neste trabalho a prática do bullying homofóbico nas aulas de Educação Física. Também permite situar o problema, analisando criticamente o estado atual do conhecimento, comparando e contrastando, "de modo a identificar pontos de consenso, bem como controvérsias, regiões de sombra e lacunas que merecem ser esclarecidas" (p.180).

Para verificarmos a produção em Educação Física sobre nosso tema, fizemos buscas em bases de dados eletrônicos de periódicos nacionais da área, sendo eles: Movimento (Qualis A2), Revista Brasileira de Ciências do Esporte - RBCE (Qualis B1), Motriz (Qualis B1), Pensar a Prática (Qualis B2), Revista da Educação Física da UEM (Qualis B1) e Revista Brasileira de Educação Física e Esporte - RBEFE (Qualis B1). Consideramos o período de publicação entre 2006 e 2014.

Os critérios de escolha dos periódicos foram a classificação no Qualis CAPES ${ }^{9}$ da área de Educação Física. Para fazer o levantamento dos artigos nos periódicos nacionais, via bases de dados eletrônicos, utilizamos os seguintes descritores; i. bullying e Educação Física; ii. bullying e homofobia; iii. bullying homofóbico; e iv. homofobia e Educação Física.

Reconhecendo nossas questões investigativas de estudo, escolhemos como referencial teórico de análise dos dados e interpretação dos resultados a Análise de Conteúdo, preconizada por Bardin (2011), mais especificamente em sua representação categorial. Este recurso ou procedimento de análise se dá a partir da totalidade do texto, classificando por frequência de presença ou ausência os itens de sentidos direcionados à indagação do estudo em questão. Assim sendo, estabelecemos categorias temáticas relacionadas com o objetivo deste trabalho, sendo elas representadas pelos descritores.

A respeito do procedimento de análise, vale ressaltar que ele se deu a partir dos seguintes critérios: i. levantamento dos artigos relacionados ao bullying e à sua possível relação com a hom ofobia através do título, palavras-chave, resumo e objetivos; ii. mapeamento e relação de todos os artigos relacionados ao objetivo do estudo; iii. leitura integral e analítica dos artigos que apresentaram uma relação explícita com o tema ou que possibilitaram o melhor delineamento da pesquisa; iv. elaboração do gráfico relacional entre descritores e incidência de artigos nos periódicos; quadro categorial de análise geral; v. tabela de número e percentual de artigos; vi. quadro categorial geral de análise dos periódicos e dos artigos; vii. gráfico numérico com percentual relacionado aos descritores.

\section{EXCURSO SOBRE O BULLYING}

O bullying caracteriza-se como um conjunto de atitudes agressivas, intencionais e repetidas de maneira insistente e perturbadora. Elas ocorrem sem motivação aparente ou evidente e na forma "velada", sendo adotadas por uma ou mais pessoas contra outra(s), dentro de uma relação desigual de poder. Esse fenômeno se manifesta, sutilmente, sob

9 O QUALIS é uma medida indireta que avalia a qualidade do periódico, com base no fator de impacto, calculado de acordo com a quantidade de vezes que um artigo é citado por outros artigos. (TEIXEIRA et al., 2012, p.421). 
a forma de brincadeiras, apelidos, trotes e gozações, sendo cada vez mais presente no ambiente escolar (FANTE, 2005; CAPINUSSÚ, BOTELLHO, 2007).

Magalhães (2004) afirma que, enquanto a violência física deixa marcas visíveis pelo corpo, hematomas, cicatrizes, sangramentos, deformações nos ossos ou problemas neurológicos; as agressões psicológicas deixam marcas comportamentais difíceis de serem diagnosticadas. Mesmo quando existe a mudança de comportamento aparente - por meio de estados depressivos, apatia ou agressividade - as causas desses transtornos são, muitas vezes, confundidas, pois a maioria dos alunos e alunas sofre em silêncio. Isso exige que o professor(a) e demais sujeitos sociais envolvidos na comunidade escolar tenham um maior preparo e uma sensibilidade aguçada para contribuir com o combate a esse violento fenômeno.

O bullying escolar pode acarretar diversas complicações na vida dos indivíduos que o recebem podendo incidir no comportamento global da vítima, comprometendo seu desenvolvimento biopsicossocial. Os efeitos incluem o comprometimento do ego, a dependência emocional, além de danos na autoconfiança, na percepção do mundo e da realidade (FANTE, 2005). Segundo Candau (2003), a criança vítima de bullying tende a se tornar um adulto antissocial, com baixa autoestima, inseguro, retraído, introvertido, com dificuldade de estabelecer relações interpessoais estáveis. O medo de ser abandonada e o sentimento de rejeição costumam sempre se fazerem presentes nessas pessoas.

Magalhães (2004) aponta a necessidade de medidas interventivas na escola em parceria com a família, considerando esse espaço como importante na formação dos indivíduos. Os contextos familiares vulneráveis, marcados por agravantes como o alcoolismo e as drogas, devem receber atenção especial, assim como o despreparo de docentes para tratar desse tema. Posto isso, abaixo traremos algumas discussões importantes para o entendimento e fundamentação das problematizações mais específicas ligadas ao bullying, considerando sua possível relação com a homofobia, principalmente, no contexto escolar. Há de se destacar nesse processo as questões relacionadas a gênero, sexualidade e cultura.

O movimento feminista, iniciado na década de 1960, chamou a atenção para formas de dominação até então pouco problematizadas. Ele foi responsável por dar visibilidade a questões de gênero presentes na sociedade. Um dos principais méritos desse movimento foi a problematização dos padrões comportamentais de masculinidade e feminilidade como constructos culturais, distanciando do debate biologicista que os entendiam como componentes genéticos (LOURO, 1999). Segundo Goellner (2001):

[...] identidade de gênero é a construção social do sexo destacando e identificando-se como feminino e/ou masculino interpretados como plurais, rompendo com a lógica binária da identidade de sexo que determina como o sujeito vive a sua sexualidade e dirige o seu prazer/desejo em relação ao outro sexo (p.223).

Quanto à sexualidade, cabe destacar que ela também se envolve e se constrói a partir e com diversos processos culturais, sendo eles relacionados a rituais, linguagem, fantasias, representações, símbolos, convenções etc. Portanto, as identidades de gênero 
e a sexualidade são compostas e definidas por relações sociais que, por suas vezes, são moldadas na cultura e na história, por redes de poder de uma sociedade.

O sexo pode ser considerado como uma referência para as categorias de masculino e feminino sob o aspecto biológico ${ }^{10}$, enquanto gênero refere-se à soma das características psicossociais consideradas apropriadas aos membros de cada grupo sexual. É nesse viés que gênero torna-se constituinte do sujeito e muda de acordo com o tempo, sociedade, dentre outros fatores. (LOURO, 1999).

Segundo esta autora, esse contexto divide binariamente os seres humanos em masculinos e femininos, realinhando as categorias de gênero numa composição discursiva em que as práticas sociais são percebidas no interior da norma heterossexual dualizante (LOURO, 2004). Assim, a homossexualidade passa a ser vista como desvio, pois desconstrói o dualismo homem/mulher em torno do qual a sociedade ocidental organiza-se e legitima-se.

\section{IDENTIDADE DE GÊNERO E IDENTIDADE SEXUAL}

Para Goellner $(2001 ; 2005)$ a identidade sexual centra seu foco na forma com que cada sujeito vive sua sexualidade, ou seja, seus desejos e prazeres corporais, podendo ser eles com pessoas do mesmo sexo, do sexo oposto, de ambos os sexos ou sozinho. Podemos, então, pensar na construção de identidade sexual a partir das diferentes formas pelas quais os indivíduos exercem sua sexualidade, rompendo com a ideia de uma essência masculina e feminina.

Hoje, são sugeridas, anunciadas e promovidas socialmente várias formas de sentir prazer e desejos corporais de maneira mais frequente que algumas décadas atrás. Essas formas de sentir prazer e desejos corporais, por vezes, tendem a ser reguladas, negadas e até mesmo condenadas, porém, as contribuições dos movimentos feministas, de gays e lésbicas, sustentam e encaminham esse debate em um viés que entendemos como progressista. Tal debate tem se tornado cada vez mais acalorado devido à oposição de pessoas e instituições que se sentem ideologicamente ameaçadas.

A partir do esclarecimento, novas identidades sociais tornaram-se visíveis, provocando em seu processo de afirmação e diferenciação novas divisões sociais e o nascimento do que passou a ser conhecido como "política de identidades" (HALL, 1997). Atualmente, existem fortes tensionamentos a ideia de que a heterossexualidade é algo natural, indo na direção de que ela é, na verdade, compulsória, visto que cada vez mais se aumenta o número de adeptos ao novo formato da diferenciação de gêneros. Diante da incompreensão dos elementos trazidos até aqui, intolerantes emergem na prática do bullying homofóbico (LOURO, 2004).

10 Sobre essa diferenciação, Butler (1992) questiona a equação linear entre sexo biológico, identidade de gênero e identidade sexual, problematizando que até mesmo o sexo, interpretado enquanto uma instância biológica, sofre investimentos dos sujeitos, como por exemplo, a decisão de mudança de sexo por homens e mulheres. Nestes casos, os sujeitos interferem na própria biologia, indicando que o sexo, além de biológico, detém uma carga socialmente construída. 


\section{O BULLYING HOMOFÓBICO E SUAS REPRESENTAÇÕES}

Fante (2005) aponta a dificuldade do trabalho contra o bullying homofóbico por se tratar de uma prática enraizada na cultura patriarcal, tida como normal, sendo por vezes incentivada pela família e até mesmo por professores. Para o autor, a prática do bullying contra homossexuais e contra os "considerados" homossexuais a partir de seus trejeitos é transversal, isto é, ocorre em todas as classes, podendo, inclusive, estar associada à violência física. As práticas de maus-tratos decorrem da confluência entre diferentes fatores desencadeantes.

O termo homofobia emergiu na década de 1970 buscando definir a aversão à homossexualidade numa sociedade de matriz heteronormativa. A homofobia é frequentemente caracterizada como ódio irracional aqueles/as que são homossexuais. Porém, a homofobia, a lesbofobia, a transfobia e a bifobia não atingem somente quem é gay, mas lésbicas, bissexuais e transexuais, que em determinadas circunstâncias mostram-se, ou são vistos/as com características socialmente consideradas “impróprias" para o seu sexo/gênero, como já destacamos (BORRILLO, 2010).

Assim, juntos, o bullying e a homofobia, a lesbofobia, a transfobia e a bifobia caracterizam um composto de fatores que colaboram para a agressão aos sujeitos tidos como "homossexuais", "lésbicas", "bissexuais" ou "transexuais" nos diversos ambientes. Para Azevedo (2009), principalmente na escola, a homofobia pode ser interpretada como uma forma de bullying, visto que ambos os conceitos possuem sentido cultural e social.

O bullying homofóbico consiste em uma forma contundente de discriminação, já que alguns homossexuais são entendidos como transgressores das regras sociais normativas, ou, em outras palavras, como transgressores do comportamento "normal", imposto pela heteronormatividade, ainda que muitos "homossexuais" se mantenham invisíveis nesse contexto, alguns se passando por heterossexuais inclusive, com a finalidade de não sofrerem violência de ordem simbólica ou física. A naturalização da heterossexualidade como a única forma apropriada de orientação sexual faz com que qualquer outra identidade sexual seja rotulada como desviante, diferente e, por conseguinte, discriminada.

A escola é um espaço privilegiado para a observação e intervenção da prática do bullying devido à heterogeneidade de seus alunos. Porém, por meio de várias estratégias e táticas equivocadas, a escola acaba caminhando na contramão, "fixando" identidades masculinas ou femininas "normais" e duradouras, devido a oscilações, contradições e fragilidades que marcam seu investimento cultural. Isso fica explícito na definição, por exemplo, de banheiros "masculinos" e "femininos", filas de meninos e meninas, ou vestimentas distintas para eles e elas na escola.

As coisas se complicam ainda mais para aqueles e aquelas que se percebem com interesses ou desejos que não se enquadram nas normas de identidade sexual heterossexual. Para esses restam poucas alternativas devido à homofobia exercer uma função de obstáculo à vida pública, afetando as esferas social, psicológica e econômica, gerando um ônus à sua vítima. Como consequência, os estudantes que são vítimas dessa violência internalizam e aceitam o preconceito ou não sabem como agir, devido à falta de orientação e até mesmo pelo despreparo dos professores. 
Nas aulas de $\mathrm{E}$ d u cação Física, as formas de bullying tendem a exprimir-se com mais veemência devido à liberdade e, principalmente, pela socialização marcada pelas práticas corporais grupais que acabam deixando os significados culturais e suas diferenças mais expostos (LOUZADA, DEVIDE, 2006). O corpo, o movimento e a expressão corporal podem ser instrumentos potentes de diagnóstico e de intervenção do bullying, em especial o homofóbico.

De acordo com Devide; Peçanha (2010) geralmente, as vítimas de bullying são alunos inseguros, "desesperançados", com baixa autoestima, apresentando comportamento estereotipado, em que estes autores interpretaram como sendo diferente da maioria dos alunos da escola pesquisada. Torna-se importante então saber como as pesquisas em Educação Física estão se delineando diante dessa discussão, sendo esse o objetivo do próximo tópico deste artigo.

\section{DESCRIÇÃO E ANÁLISE DOS DADOS}

Os dados coletados nos seis periódicos da Educação Física, considerando o período de publicação entre 2006 a 2014, ${ }^{11}$ apontam para um total de quatorze artigos relacionados aos descritores pesquisados: i. bullying e Educação Física; ii. bullying e homofobia; iii. bullying homofóbico; iv. homofobia e Educação Física.

Somente dois dos descritores utilizados para o levantamento nas bases de dados eletrônicas apresentaram respostas positivas para a existência de artigos (GRÁFICO I e TABELA I), sendo eles: bulliyng e Educação Física e homofobia e Educação Física. Cabe destacar que o último descritor foi proposto após a ausência de pesquisas que tinham como temática principal o bullying de forma relacional com a homofobia, a fim de sabermos se ao menos nos trabalhos voltados para a centralidade da discussão da homofobia eram estabelecidas reflexões a respeito do bullying homofóbico. É importante frisar que como justificativa dessa ausência pode ser incorporada as críticas ao uso desse enunciado, como apontam Diaz; Souza (2010).

11 A escolha do marco temporal deu-se de forma aleatória, ou seja, foi apenas uma maneira de delimitar o período. 


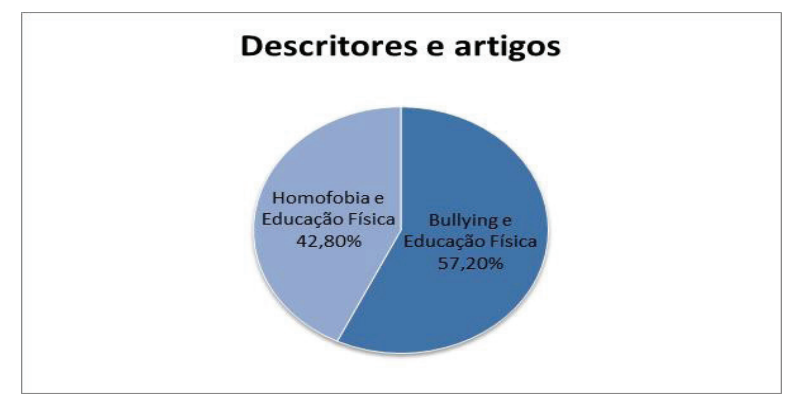

Gráfico I - Relação entre descritores e incidências de artigos nos periódicos. Fonte: dos autores

No total, encontramos 08 artigos voltados para a problematização do bullying na Educação Física e 06 artigos ligados à homofobia e a Educação Física Nenhum dos 06 artigos sobre homofobia e Educação Física fez menção ao bullying homofóbico.

Tabela I - Número e percentual de artigos de acordo com os descritores pesquisados.

\begin{tabular}{lcc}
\hline Descritores & Quantidade & Percentual \\
\hline Bullying e Educação Física & 08 & $57,2 \%$ \\
Bullying e homofobia & 00 & $00,0 \%$ \\
Bullying homofóbico & 00 & $00,0 \%$ \\
Homofobia e Educação Física & 06 & $42,8 \%$ \\
\hline
\end{tabular}

Fonte: dos autores

Os periódicos que comportam os artigos com os temas dos descritores pesquisados se organizaram da seguinte maneira: i. Revista Movimento: 01 artigo sobre bullying e Educação Física, 02 artigos sobre Homofobia e Educação Física; ii. Revista Motriz: 01 artigo sobre homofobia e Educação Física; iii. Revista Brasileira de Educação Física e Esporte: 02 artigos sobre bullying e Educação Física e 02 artigos sobre homofobia e Educação Física; iv. Revista Brasileira de Ciências do Esporte: 01 artigo sobre bullying e Educação Física; v. Revista Pensar a Prática: 04 artigos sobre bullying e Educação Física e 01 artigo sobre homofobia e Educação Física. 
julho/2018

Tabela II - Quadro geral de análise dos periódicos e dos artigos de acordo com os descritores.

\begin{tabular}{lcccc}
\hline \multirow{2}{*}{ PERIÓdICOS } & \multicolumn{5}{c}{ DESCRITORES } \\
\cline { 2 - 6 } & $\begin{array}{c}\text { Bullying e } \\
\text { homofobia }\end{array}$ & $\begin{array}{c}\text { Bullying } \\
\text { Homofóbico }\end{array}$ & $\begin{array}{c}\text { Bulliyng e } \\
\text { Educação Física }\end{array}$ & $\begin{array}{c}\text { Homofobia e } \\
\text { Educação Física }\end{array}$ \\
\hline Movimento & - & - & 01 & 02 \\
Motriz & - & - & - & 01 \\
RBEFE & - & - & 02 & 02 \\
RBCE & - & - & 01 & - \\
Pensar a prática & - & - & 04 & 01 \\
UEM & - & - & - & $\mathbf{1 4}$ \\
\end{tabular}

Fonte: dos autores

\section{Bullying e Educação Física}

Os oito artigos encontrados a partir do descritor bullying e Educação Física estavam dispostos em quatro periódicos dos seis pesquisados: Revista Movimento (01); Revista Brasileira de E.F. e Esporte (02), RBCE (01) Revista Pensar a Prática (04):

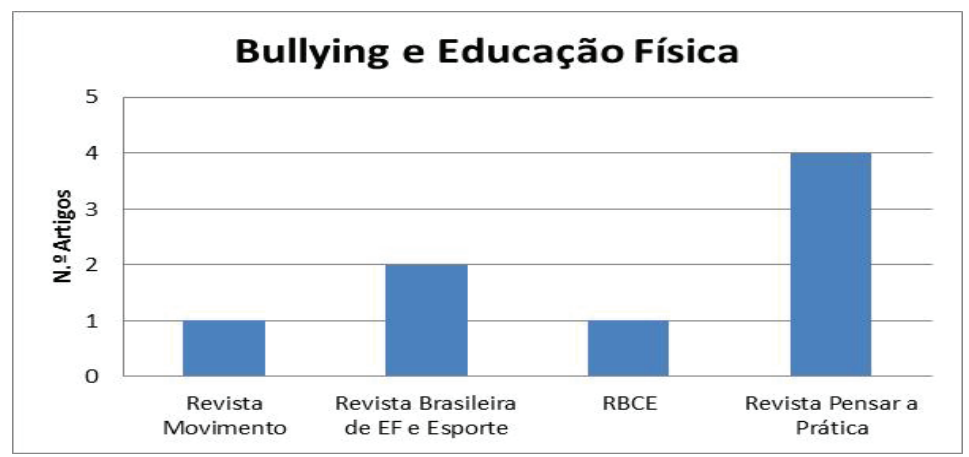

Gráfico II - Incidência de artigos a partir do descritor Bullying e Educação Física nos periódicos pesquisados.

Fonte: dos autores

Quando cruzamos os dados dos artigos dispostos nos periódicos com o descritor pesquisado emergiram algumas tendências específicas. Entre os artigos dispostos no periódico Pensar a Prática, por exemplo, foi possível perceber que os estudos se pautam, majoritariamente, em entrevistas e observações informais como estratégias metodológicas: 
(...) Para verificar os alunos envolvidos em bullying utilizando o roteiro de Dan Olweus (1989) adaptado por Nogueira (2007), e através de observação informal nos horários das aulas de educação física, no recreio durante um período de 4 meses (LEVANDOSKI; FERNANDO, 2010).

(...) Foram selecionadas as quatro maiores escolas da rede municipal de Itaperuna e aplicado um questionário sobre bullying em 141 estudantes (LINHARES; FARIA; LINS, 2013).

Quanto aos objetivos, percebemos que os quatros artigos buscam analisar ocorrências e recorrências do fenômeno bullying nas aulas de Educação Física. Fica aparente também a busca pelo entendimento de como o bullying se delineia, quais seus tipos mais comuns, quem o pratica e como as vítimas e os professores reagem a tal fato:

O objetivo foi analisar a maneira com que os alunos administram suas situações de conflito e verificar a existência do fenômeno bullying em escolares (LEVANDOSKI; FERNANDO, 2010).

O objetivo foi analisar a relação do gênero com os tipos de bullying mais frequentes nas aulas de Educação Física Escolar do $6^{\circ}$ ano do Ensino Fundamental (LINHARES; FARIA; LINS, 2013).

Objetivo: investigar a existência e sob que forma o bullying ocorre nas aulas de educação física em uma escola do Distrito Federal (BOMFIM et al, 2012).

Ainda entre os artigos relacionados ao bullying e a Educação Física, as análises a respeito dos periódicos Revista Movimento, Revista Brasileira de Educação Física e Esporte e RBCE, que juntos totalizam quatro artigos, observamos o extravasamento da relação Bullying - Educação Física - Corpo para o espaço virtual:

[...] Nós estudamos o bullying no ambiente virtual, a fim de tentar compreender sua ocorrência no tempo de lazer de alunos do ensino médio. (...) Analisamos as formas como os membros dessas comunidades praticam o cyberbullying sobre colegas da escola, sendo que o corpo é o foco principal das agressões. Entendemos que aulas de educação física tanto podem reproduzir quanto questionar esse tipo de assédio, ainda que esse comportamento desviante de cyberbullying seja resultante do amplo contexto cultural e social dos adolescentes (GONÇALES; PIMENTEL; PEREIRA, 2014).

No mais, os últimos quatro artigos citados acima sinalizam também para a identificação e entendimento do bullying. Seus objetivos visam, além da identificação da ocorrência/ recorrência do bullying, à percepção dos sentimentos das vítimas e ao levantamento de possíveis contribuições da Educação Física frente a esse fenômeno.

Analisamos as formas como os membros dessas comunidades praticam o cyberbullying sobre colegas da escola, sendo que o corpo é o foco principal das 
agressões. Entendemos que aulas de educação física tanto podem reproduzir quanto questionar esse tipo de assédio, ainda que este comportamento desviante de cyberbullying seja resultante do amplo contexto cultural e social dos adolescentes (GONÇALES; PIMENTEL; PEREIRA, 2014).

O presente estudo teve como objetivo identificar a ocorrência de situações de violência e bullying nas aulas de Educação Física, bem como o sentimento dos alunos que vivenciaram e/ ou sofreram com tais situações durante as aulas (WEIMER; MOREIRA, 2014).

Algumas outras ideias e possibilidades de intervenção foram encontradas nos artigos analisados nesse tópico. Dentre elas, destacam-se a importância da compreensão da realidade da escola, a necessidade uma boa formação inicial e continuada e à criação de meios ou programas que permitam a discussão dos temas relacionados à violência, agressões e bullying (WEIMER et al., 2014).

\section{BULLYING E HOMOFOBIA, BULLYING HOMOFÓBICO E HOMOFOBIA E EDUCAÇÃO FÍSICA}

Nessa tendência, como já destacado, o que emerge do conjunto de artigos pesquisados a partir dos descritores bullying e homofobia e bullying homofóbico nos periódicos, é a ausência de investigações que estabelecem a relação bullying-homofobia na Educação Física ou, ao menos, no cenário principal de periódicos da área. A partir disso, visando confirmar se realmente a relação citada acima não se faz presente, optamos pela utilização de um último descritor: homofobia e Educação Física

A partir desse descritor, foram encontrados seis artigos distribuídos em quatro dos seis periódicos pesquisados: Revista Movimento (02), Revista Motriz (01), Revista Brasileira de Educação Física e Esporte (02) e Revista Pensar a Prática (01).

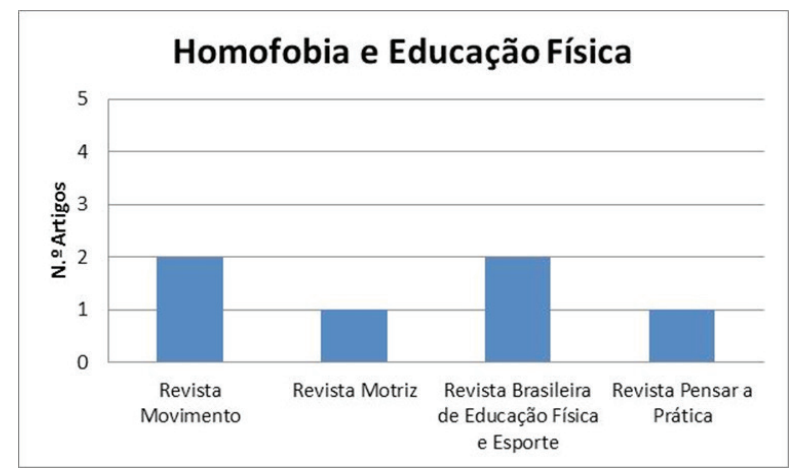

Gráfico III - Incidência de artigos a partir do descritor "Homofobia e Educação Física" nos periódicos pesquisados. 
A revista Movimento e a Revista Brasileira de Educação Física e Esporte foram as que apresentaram mais artigos relacionados à temática homofobia e Educação Física, num total de quatro publicações. Nesse descritor, verificamos que os artigos dispostos nos periódicos pesquisados direcionam suas análises para questões e representações de gênero, sexualidades, homofobia no espaço escolar e nas aulas de Educação Física, porém, sem relação direta com o bullying:

Este estudo tem como objetivo analisar representações de masculinidade hegemônica no âmbito da disciplina curricular Educação Física no sistema educativo português (SILVA; GOMES; GOELLNER, 2008).

Procuramos compreender como são atribuídos significados de gênero que constituem modos diferenciados de ser menino ou menina no espaço do recreio de uma escola pública de Porto Alegre, no Brasil (WENETZ; STIGGER; MEYER, 2013).

Problematizamos as interlocuções entre corpo, gênero, identidade e cultura corporal de movimento. As práticas corporais e esportivas educam os corpos para além de suas performances, saúde e beleza. Suas "verdades" produzem marcas associadas ao gênero e à sexualidade em um processo cultural de marcação de diferenças (...) atreladas a categorias binárias como (...) homem-mulher, heterossexual-homossexual. (PRADO; MIRANDA, 2010).

O objetivo deste estudo foi investigar a opinião dos professores de Educação Física do Ensino Médio sobre a homossexualidade e a homofobia na escola, através de um estudo exploratório (OLIVEIRA; GODOI; SANTOS, 2014).

Os artigos também propõem possibilidades pedagógicas para as aulas de Educação Física visando estabelecer pontes reflexivas relacionadas às questões de gênero, sexualidades e práticas corporais, como demonstra o exemplo abaixo:

Após essas atividades o/a professor/a poderia propiciar espaços para que os alunos e alunas se manifestassem em relação a tais práticas, sendo que através de algumas questões norteadoras, um debate rumo a criticidade e reflexão poderia ser mediado. (PRADO et al, 2010, p. 410).

Mesmo o bullying homofóbico sendo uma realidade nas escolas e na vida de crianças e jovens estudantes, é confirmada novamente a tendência de sua escassez nas pesquisas da Educação Física brasileira, aos menos nos periódicos pesquisados, caracterizando-se como uma lacuna nos Estudos de Gênero já apontada por estudos anteriores (DEVIDE et al, 2011).

Pesquisas são imprescindíveis por exercerem a crítica e a orientação sobre determinadas temáticas, propiciando aos docentes esclarecimentos e ferramentas para intervenções que se fizerem necessárias na prática pedagógica. Sendo assim, a superação dos comportamentos preconceituosos ligados ao bullying homofóbico parece se encontrar 
ainda distante de ser resolvida nas aulas de Educação Física. Além da escassez de estudos e pesquisas que contemplem essa temática, se faz necessária à presença de campanhas educativas acerca da valorização da diversidade, seja essa de gênero, identidade, raça, religião, classe social, entre outras categorias. Esse debate necessita extrapolar os muros das escolas, sendo pauta em outras instituições sociais, como a família, a legislação e o mundo do trabalho.

\section{CONSIDERAÇÕES FINAIS}

A escola, em princípio, consiste em uma instituição investida de papel formador nos aspectos cognitivos, culturais, sociais e morais. É em seu interior de que crianças e adolescentes passam a maior parte de seu tempo e aprendem grande parte dos ensinamentos que os acompanharão ao longo da vida. Todavia, o fato de práticas como o bullying serem constantes nesse espaço institucional, leva-nos a indagar se a escola tem, realmente, desempenhado de forma efetiva seu papel educativo, com foco na inclusão e na democracia. Diante dessa reflexão, nossos objetivos pretendiam não apenas perceber o índice de publicações a respeito do bullying e suas características/objetivos nos principais periódicos da Educação Física de acordo com a CAPES. Neles buscávamos, também, investigar a relação com a homofobia, ou bullying homofóbico, verificando as estratégias de intervenção p ropostas pelos p rofessores nas aulas de Educação Física.

Após a análise dos dados, percebemos que o fenômeno bullying, apesar de ser pouco estudado, se faz presente nas pesquisas da Educação Física. A discussão de tal fenômeno em relação à homofobia não apresentou resultados em nossa pesquisa. Fato que nos leva a crer que, nos periódicos pesquisados, ainda não se fazem existentes estudos voltados para o bullying homofóbico. Sendo os periódicos estudados os principais da Educação Física, podemos inferir a ausência do debate na área. Assim, não foi possível detectar as estratégias de intervenção para as aulas de Educação Física quando esses comportamentos emergem. Os artigos sugerem apenas alternativas para minimizar conflitos relacionados ao bullying ou à homofobia, a partir de análises de ocorrência e recorrências nas aulas. Outro ponto destacado se deu na percepção dos sentimentos das vítimas e no levantamento de possíveis contribuições da Educação Física frente a esse fenômeno. Dentre elas, pode-se destacar a importância da compreensão da realidade da escola, a necessidade uma boa formação inicial e continuada e à criação de meios ou programas que permitam a discussão dos temas relacionados à violência, agressões e bullying.

Finalmente, compreendemos como importante que estudos se atentem à problematização de possibilidades de intervenção a respeito do bullying homofóbico nas práticas corporais desenvolvidas nas aulas de Educação Física. Isso devido ao cenário privilegiado para que esse tipo de intolerância apareça. Essa medida contribui para que os alunos possam exercer/construir seus processos de cidadania e de liberdade como sujeitos sociais. 


\section{REFERÊNCIAS}

ALVES-MAZZOTTI, Judith.; GEWANDSZNAJDER, Fernando. O método nas Ciências Sociais e Naturais: pesquisa quantitativa e qualitativa. 2:ed. São Paulo: PioneiraThomson, 2002 AZEVEDO, Leonardo Francisco de. Bullying e homofobia na escola: processo de construção de identidades e o estranhamento do outro. In: RAM 2009. VIII Reunión de Antropologia del Mercosur. Disponível em: < http://www.ram2009.unsam.edu.ar/ GT/GT $\% 2017 \% 20 \%$ E2\%80\% 93\%20Deseos $\% 20$ que $\% 2$ Confr ontan $\% 20$ Estudios $\% 20$ sobre \%20Sexualidades \%20Dissidentes/GT17- Ponencia\%5BAzevedo\%5D.pdf> Acesso em: 03/07/2017.

BARDIN, Laurence. Análise de conteúdo. São Paulo: Edições 70, 2011.

BOMFIM, Daiane Lopes et al. Ocorrência de bullying nas aulas de Educação Física em uma escola do distrito federal. Pensar a Prática, v. 15, n. 2, jun. 2012.

BORRILLO, Daniel. Homofobia: história e crítica de um preconceito. Belo Horizonte: Editora Autêntica, 2010.

BUTLER, Judith. Problema de los géneros, teoría feminista y discurso psicoanalítico. In: NICHOLSON, J. Linda (Org.). Feminismo/posmodernismo. Buenos Aires: Feminaria Editora, 1992. p. 75- 95

CANDAU, Vera Maria. Somos todos iguais? Escola, discriminação e educação em direitos humanos. Rio de Janeiro: DP\&A, 2003.

CAPINUSSÚ, José Maurício; BOTELHO, Rafael Guimarães. 'Bullying' e Educação Física na Escola: características, casos, consequências e estratégias de intervenção. Revista de Educação Física, n. 39, dez./ 2007.

DEVIDE, Fabiano Pries. et al. Estudos de Gênero na Educação Física. Motriz, v.17, n.1, p.93-103, 2011.

DEVIDE, Fabiano Pries; PEÇANHA, Morjana Brito. O discurso dos docentes do primeiro segmento do ensino fundamental sobre o bullying homofóbico na Educação Física escolar. Revista Digital-Buenos Aires, año 15, n.146, p.1-11, Jul/2010.

DIAZ, Gabriela Andrea; SOUZA, Mériti de. Bullying homofóbico: um nome "diferente" para a violência? In: Seminário Internacional Fazendo Gênero, 9., 2010, Florianópolis. Anais eletrônicos... Florianópolis: Seminário Internacional Fazendo Gênero, 2010. Comunicações Livres. Disponível em: < http://www.fazendogenero.ufsc.br/9/resources/ anais/1278250298_ARQUIVO_artigofazendogeneroformatado4-7-2010ultimo.pdf $>$. Acessado em: 08 de agosto/2017.

FANTE Cleo. Fenômeno bullying: como prevenir a violência e educar para a paz. São Paulo: Verus, 2005.

GOELLNER, Silvana Vilodre. Gênero, Educação Física e Esportes. In.: Votre, Sebastião José. (org.). Imaginário e Representações Sociais em Educação Física, Esporte e Lazer. Rio de Janeiro: UGF, p. 215-227. 2001.

GOELLNER, Silvana Vilodre. Gênero. In: FENSTENSEIFER, Paulo Evaldo; GONZÁLEZ, Fernando Jaíme. Dicionário Crítico de Educação Física. Ijuí: Unijuí, 2005, p. 205-207. 
julho/2018

GONÇALES, Cynara; PIMENTEL, Giuliano Gomes; PEREIRA, Beatriz. Escárnio de corpos, cyberbullying e corrupção do lúdico. Movimento, Porto Alegre, p. 965-988, maio 2014. HALL, Stuart. Identidade cultural na pós-modernidade. 11.ed. Rio de Janeiro: DP\&A, 1997 LARAIA, Roque. Cultura: um conceito antropológico. $15^{\mathrm{a}}$ ed. Rio de Janeiro: Jorge Zahar, 2001.

LE BRETON, David. A sociologia do corpo. Petrópolis:Editora Vozes; 2006.

LECH, Marlise, Agressão na escola: como entender e lidar com essa questão. Porto Alegre. Ed. Mediação, 2007.

LEVANDOSKI, Gustavo; CARDOSO, Fernando Luiz. Percepção docente sobre as relações de agressividade, Lúdico E Bullying Na Escola. Pensar a Prática, v. 13, n. 2, set. 2010.

LINHARES, Riana Duarte; FARIA, João Paulo Oliveira; LINS, Raquel Guimarães. O bullying na educação física escolar e sua diferença entre meninos e meninas. Rev. Pensar a Prática, Goiânia, v.16, n.2, p. 320-618,abr./jun. 2013.

LISBOA, Carolina; BRAGA, Luiza de Lima; EBERT, Guilherme. O fenômeno bullying ou vitimização entre pares na atualidade: definições, formas de manifestação e possibilidades de intervenção. Contextos Clínic, São Leopoldo - RS, vol.2, n.1, p. 59-71. 2009.

LOURO, Guacira Lopes. Gênero, sexualidade e educação: uma perspectiva pósestruturalista. 3.ed. Petrópolis: Vozes, 1999.

LOURO, Guacira Lopes. Um corpo estranho: ensaios sobre sexualidade e teoria 'queer'. Belo Horizonte: Autêntica: 2004.

LOUZADA, Mauro; DEVIDE, Fabiano Pries. Educação Física escolar, co-educação e gênero: mapeando representações de discentes. Movimento, Porto Alegre, v. 12, n. 3, p. 123-140, 2006.

MAGALHÃES, Teresa. Maus tratos em crianças e jovens: guia prático para profissionais. Coimbra: Quarteto, 2004.

OLIVEIRA, Xênia Ferreira de; GODOI, Marcos Roberto; SANTOS, Luciene Neves. A opinião dos professores de educação física do ensino médio sobre a homossexualidade e a homofobia na escola. Pensar a Prática, Goiás, v. 17, n. 4, dez. 2014.

PRADO, Vagner Matias do; MIRANDA, Arilda Ines Ribeiro. Gêneros, sexualidades e Educação Física escolar: um início de conversa. Motriz, Rio Claro, v. 16, n. 2, p. 402-413, 2010.

SILVA, Paula; BOTELHO-GOMES, Paula; GOELLNER, Silvana Vilodre. Educação Física no sistema educativo português: Um espaço de reafirmação da masculinidade hegemônica. Rev. bras. Educ. Fís. Esp., São Paulo, v.22, n.3, p.219-33, jul./set 2008.

SOARES, Carmem Lúcia. et. al. Metodologia do Ensino de Educação Física. São Paulo: Cortez, 1992.

TEIXEIRA, Renan Kleber Costa, SILVEIRA, Tiago Santos; BOTELHO, Nara Macedo, PETROIANU, Andy. Citação de artigos nacionais: a (des)valorização dos periódicos brasileiros. Rev Col Bras Cir, 39(5), 2012. Disponível em: < http://www.scielo.br/pdf/ rcbc/v39n5/15.pdf > . Acessado em: 01 de ma./2017.

WENETZ, Ileana; STIGGER, Marco Paulo; MEYER, Dagmar Estermann. As (des)construções 
de gênero e sexualidade no recreio escolar. Revista Brasileira de Educação Física e Esporte, São Paulo, v. 27, n. 1, p. 117-128, mar. 2013.

WEIMER, Weyboll Rocha; MOREIRA, Evando Carlos. Violência e bullying: manifestações e consequências nas aulas de Educação Física escolar. Rev. Bras. Ciênc. Esporte, Florianópolis, v. 36, n.1, p.257-274, 2014.

Recebido em: Maio/2017 Aprovado em: Agosto/2017 